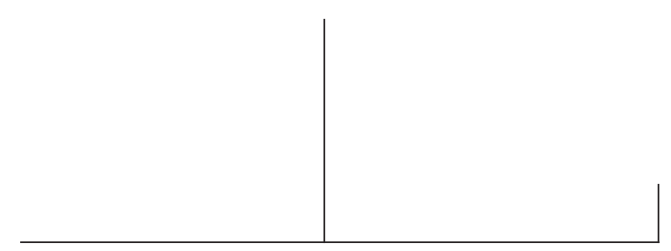

Rev. Latinoam. Psicopat. Fund., IV, 1, 27-36

\title{
Violência e alteridade: o mal-estar na adolescência*
}

\author{
Marta Rezende Cardoso
}

Explorar a articulação entre violência pulsional e adolescência é um dos objetivos principais deste trabalho no qual se procura sublinhar os aspectos traumáticos envolvidos nessa passagem. Destaca-se a questão da revivência do Édipo e, particularmente, a sua ressonância, muitas vezes também traumática, no psiquismo dos próprios pais.

Um belíssimo e trágico romance de Arthur Schnitzler (1913) - Madame Béate e seu filho - relato de múltiplas passagens ao ato, apoiadas simultaneamente nos vividos inconscientes de uma mãe e seu filho adolescente diante de um intraduzível "mal-estar”, inspira e auxilia a elaboração das idéias apresentadas.

Palavras-chave: Adolescência, violência, pulsão, complexo de Édipo

* Meus agradecimentos a Pedro Henrique Bernardes Rondon pela revisão que fez do texto e pelas produtivas trocas que mantivemos a esse propósito. 


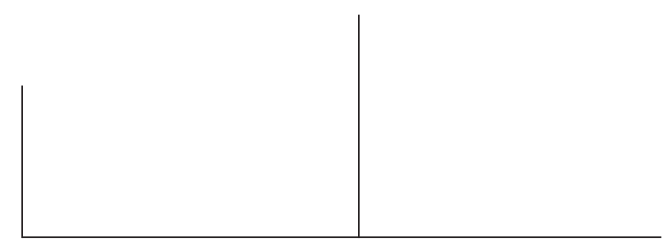

Este texto é uma tentativa de compreensão do desafio proposto à teoria e à clínica psicanalíticas não somente pelo ato violento dos adolescentes - fenômeno de grande expressão na atualidade -, mas particularmente, pela violência envolvida nos processos de subjetivação desses indivíduos, violência de caráter menos manifesto. Trata-se de buscar apreender as condições fundamentais da violência - no que tange aos processos envolvidos na gênese e no funcionamento psíquicos, levando em conta o seu entrelaçamento com a cultura, especialmente com o que se tem denominado o seu "mal-estar". Esses processos têm, inegavelmente, um papel determinante na emergência e na eventual intensificação de situações individuais e coletivas de natureza violenta. Mas, como ressalta Birman (1999), o mal-estar na civilização, tema tão central na obra de Freud, constitui, na verdade, a própria matéria-prima da teoria e da prática analíticas.

No discurso psicanalítico não é possível se pensar o sujeito na exterioridade do campo da cultura. Esta é "o outro do sujeito, sem a qual é impossível pensar as condições de possibilidade para a constituição do sujeito" (Birman, 1997). Sublinhemos, ainda, com este autor que a questão do mal-estar marca essa relação do sujeito com a cultura, à medida que é permeada pelo conflito, base do psiquismo humano e, conseqüentemente, impossível de ser solucionada de forma absoluta.

Meu interesse pelos adolescentes dentro dessa temática leva em conta, principalmente, a intensidade dos conflitos internos e relacionais implicados em suas múltiplas experiências de transformação, experiências subjetivas complexas, problemáticas, muitas vezes dolorosas e geradoras de intensa angústia e de sofrimento psíquico, e com importantes conseqüências quanto a experiências e relações sociais.

Sabemos desde Freud que o psiquismo se constrói sobre um campo pulsional. Isso implica uma situação de permanente excesso e a constante demanda de trabalho psíquico. Mas na adolescência, com suas transformações pubertárias, em primeiro lugar, há uma espécie de potencialização de todos os excessos anteriores que pareciam ter sido 


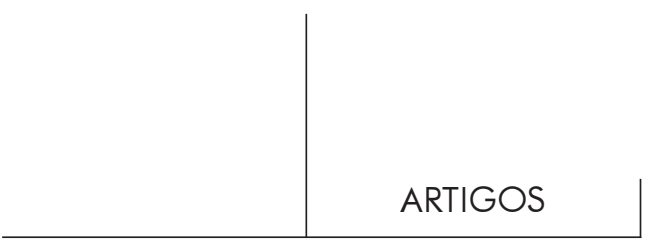

ultrapassados, elaborados. As vivências da puberdade não permitem que o sujeito possa viver as mudanças corporais e organizar o seu mundo da mesma maneira que o fazia quando criança.

No que diz respeito a essa traumática passagem, a questão das expectativas e exigências colocadas pela cultura, pelo socius, tem papel fundamental. Cada geração de adolescentes encontra dificuldades que se situam, em última instância, do lado da realidade humana e social. A crise da adolescência é também esse momento em que a confrontação com o social ou com o "mal-estar na civilização" atinge seu paroxismo. E, como observa André Green (1999), a entrada nessa fase tem como correlato a entrada dos pais numa outra idade, sendo impossível pensar a adolescência sem pensar o envelhecimento parental. Diante do caráter incontrolável dessa transformação, mobiliza-se toda a culpabilidade dos pais.

Dentro desse contexto, merece destaque a questão da revivência do Édipo, em especial as profundas modificações sofridas pelos pais diante da mudança do filho com o retorno, muitas vezes violento, de fantasias recalcadas e a reativação dos mecanismos colocados em jogo em sua própria adolescência.

Como na história do Édipo, pode-se colocar as seguintes questões a propósito das gerações: Quem seduz? Quem agride quem? A cena pubertária não é uma fantasia, mas já uma conduta ou o implícito de uma conduta na qual o adolescente tem a secreta certeza de que seus representantes edípicos têm correspondentes nos pais (Gutton, 1999: 12-13).

Sobre esse ponto, Arthur Schnitzler - escritor vienense muito admirado por Freud, presenteia-nos com o romance Madame Béate e seu filho no qual revela, mais uma vez, extrema sensibilidade ao psiquismo humano. Nesse texto encontrei uma espécie de eco às reflexões que permeiam este trabalho. Passo, então, ao relato dessa história que, de forma paroxística, ilustra a problemática da angústia e do mal-estar na adolescência, história de múltiplas e entrecruzadas passagens ao ato, espelhada no vivido de uma mãe diante da adolescência de seu filho, num complexo jogo identificatório no qual se superpõe as dimensões narcísica, edípica e alteritária.

Madame Béate, transtornada diante do "tornar-se homem" de Hugo, seu filho adolescente, é confrontada com a traumática revivência de seus conflitos inconscientes. Hugo, por sua vez, vê-se ultrapassado por seus próprios desejos e, principalmente, como iremos acompanhar, pela violência da intromissão materna, ou seja, do "enigma" materno.

Béate faz ainda o luto de seu marido, famoso ator de teatro. Agora, diante dessa nova experiência traumática - a radical mudança do filho - ela vai se defrontar com a violência de sua própria pulsão. A perda daquele homem lhe é tão enigmática quanto a estranha expressão que vem percebendo em seu filho. Angus- 


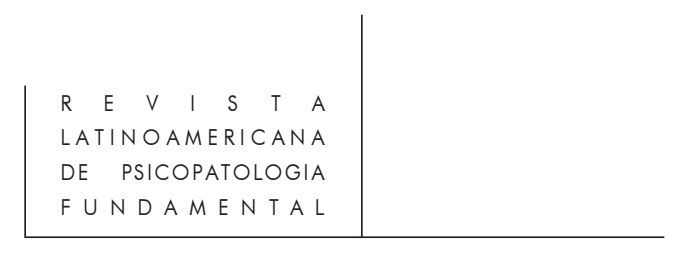

tia-se com a convicção de que alguma coisa nele - intraduzível para ela - vem se realizando. E, diante da primeira crise sentimental de Hugo, está perplexa, passiva diante desse estrangeiro. $\mathrm{O}$ temor compulsivo de que ele possa vir a ser dominado por uma mulher de má reputação a quem parece entregar-se lhe é insuportável.

Béate é invadida pelo mal-estar de sua própria adolescência por meio de confusas lembranças e sensações. Quando jovem, constata agora, ao se aproximar de seu futuro marido, Ferdinand, tentara na verdade aliar a perspectiva de uma vida honrada, de acordo com os ideais de sua educação burguesa, ao imperativo interno de paixão e aventura ilimitadas, fortemente presente nos seus anseios inconscientes. Nesse homem havia sempre visto um outro. Em seus braços acreditava ser amante de todos os outros cujo papel ele representava: "amante de heróis e devassos, de eleitos e indignos personagens, de homens misteriosos ou claros como um espelho".

Conquistou o ator contra a vontade dos pais, burgueses demais até para essa solução de compromisso, mas o conquistou, principalmente, contra um inimigo bem mais ameaçador: na ocasião, Ferdinand mantinha uma ligação com uma rica viúva, cortesã não muito jovem que o havia ajudado no início da carreira e a quem, de certo modo, ainda se submetia. Béate obstina-se em salvá-lo dessa ligação indigna e impura, decidindo-se a enfrentar diretamente essa mulher, visando a liberação definitiva dele. Essas lembranças lhe vêm à tona justamente no momento em que toma a audaciosa decisão de enfrentar a suposta amante do filho e, diante de tal missão, sente-se jovem e segura. À Fortunata, cuja exacerbada feminilidade ao mesmo tempo que a fascina desperta-lhe hostilidade indomável, ela vai finalmente declarar não suportar que Hugo seja seu amante.

Fortunata, após fazer-lhe um enigmático relato que sugere aventuras libertinas, lamenta que essa ligação seja tão condenada por Béate. Acrescenta, porém, não ter ainda cogitado de tal hipótese, mas que de qualquer forma isso não depende dela. Chocada com a resposta, Béate contesta-a: "afinal meu filho é ainda quase uma criança!" A mensagem produz uma expressão estranha e dolorosa em Fortunata que de maneira velada diz que talvez seja mesmo uma mulher perigosa, não responsável por si. Acrescenta, porém, que se tivesse um filho da idade de Hugo, que se apaixonasse por uma mulher como Béate, veria nisso a melhor iniciação.

Findo o encontro, as palavras da outra ressoam em Béate como um eco. Fantasia-a em sua doces e terríveis aventuras, "vagando com seu corpo nu como que perseguida por maus espíritos". Por que precisamente Hugo haveria de ser sua vítima? E sorri, fantasiando oferecer-lhe um substituto, o belo jovem Fritz, amigo de seu filho, seu futuro hóspede, com quem cruzara momentos antes.

Em seu caminho observa, no parque do Lago, o belo espetáculo de jovens casais divertindo-se, cena que repentinamente parece-lhe carregada de sensualidade avassaladora. Imagina o súbito desaparecimento de todos os imperativos morais; 


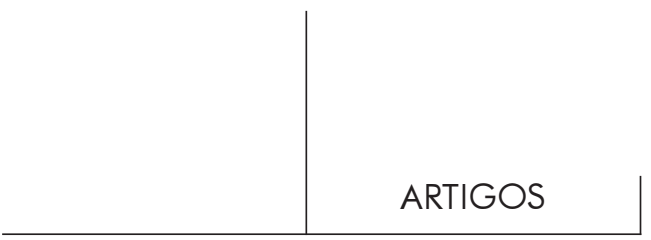

aqueles jovens seguindo seus "instintos" mais secretos, sem nenhum controle ou obstáculo - pulsões desconhecidas deles próprios. Lembra-se, então, da real existência de mundos desse tipo, sem nenhuma lei, como aquele de onde acabara de sair.

Seus devaneios são permeados por uma profunda sensação de solidão, de desamparo. Sente Hugo desaparecendo de seu horizonte, habitante que é agora de um mundo desconhecido. De volta em casa, encontra-o acompanhado de Fritz, maduro e sedutor, diante do qual Hugo aparenta ser bem mais infantil, e isto a tranquiiliza. Mas sabe - e a figura da sedutora nela retorna - que nunca mais poderá acariciar e beijar os lábios daquela criança como outrora. Ela o havia perdido e estava só. Quantas noites terá ele ficado com ela? Tudo se tornou enigmático, "nada mais pode saber de seu menino que se tornou homem nos braços de uma cortesã".

Embora internamente dividida, decide sair de sua reclusão de viúva. Passando pela casa de Fortunata, diante da pequena luz que, atenta, observa, angustia-se. Ante a ameaçadora fantasia que a invade, recusa-a, perguntando-se: mas o que isso podia lhe importar? Chega ao terraço do Hotel do lago, reunindo-se a um grupo de amigos dentre os quais o jovem Fritz. Inquieta-se com a ausência de Hugo. Sim, agora tem certeza de que àquela hora ele está com Fortunata, e esta não deve ser a primeira vez. Nela impõe-se, então, a visão de um ato que a faz tremer e esconder o rosto entre as mãos, como que desejando expulsá-lo de sua consciência. Sente novamente aquela profunda tristeza, como que se despedindo de algo que nunca mais poderá rever. Nessa mesma noite, Fritz a assedia de forma direta e invasiva, ato que a assusta e lhe parece impulsivo e louco.

Volta para casa e a angústia com a falta de Hugo persiste. Pensa se não é estranho que a mãe de um filho que passa suas noites com uma amante possa ainda ser desejada. Mas por que seria isso estranho, indaga-se ela, jovem que era ainda, talvez até mais jovem do que Fortunata? Nesse momento é surpreendida pelo retorno de Fritz. De onde estaria vindo? Teria ele também uma pequena aventura ali por perto? Nessa mesma noite, com dolorosa excitação, intenso prazer e culpa, Madame Béate vai se entregar a Fritz, de quem se tornará amante.

Ah, se ele pudesse nunca mais voltar, se pudesse novamente estar sozinha com seu Hugo, como antes. Partir! Partir! Partir! Precisava fugir daquela situação antes que algo irreparável acontecesse. "Antes que a reputação da mãe fosse anulada e a juventude do filho corrompida. Antes que a força do destino viesse se abater sobre os dois." Como convencer o filho a partir tão bruscamente? O poder daquela mulher devia ser, sem dúvida, muito forte. Relembra as carícias de seu amante de quem, com muita dor, decide despedir-se para sempre. Será capaz de resistir a ele? Resistirá ela a seu próprio desejo?

Pensa em seu ato como completamente estrangeiro a ela, como uma doença que a dominou, deixando-a indefesa e fora de si. Sente medo, horror e desejo 


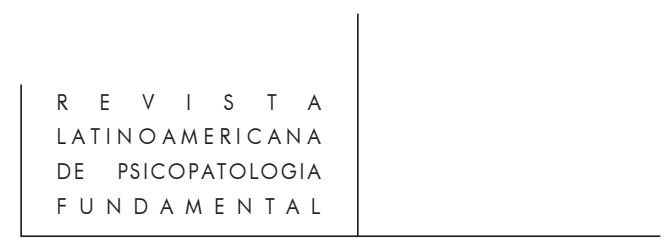

diante de sua lembrança. Não havia tempo a perder. Abre abruptamente a porta e está diante do quarto de Hugo. Entra, sobressaltando-o com sua inesperada visita. Diante da profunda angústia que ele transmite, imagina que ele sabe de tudo. Deixa-o chorar, acariciando docemente seus cabelos, sem deixar, porém, de se perguntar o que poderia ter acontecido. Obstina-se em saber, a qualquer preço; ele deve tudo lhe dizer, como antes. Quem sabe num passeio noturno em torno daquele lago tão familiar, o medo de falar não se dissiparia? No espaço sombrio do bosque ela entra impulsivamente no barco, seguida por ele que apanha também um dos remos para ajudá-la a conduzi-lo. Volta a perguntar sobre o que se passou. O que Fortunata teria feito com ele? Que ato teria sido este? Ele lhe implora que cesse de interrogá-lo: é terrível demais. Isso excita ainda mais a sua curiosidade. Parecialhe que finalmente "da confusão deste dia, pleno de enigmas, antigos e novos, viria alguma resposta". Fale, insistia ela, afirmando ser, além de mãe, também mulher. Ah se ele soubesse! E a resposta vem: "eu sei, mãe". Hugo não revela seu segredo e diz apenas que nunca mais poderá reaparecer no mundo dos homens. Teria perdido a cabeça, não sabe exatamente o que se passou. "Eles me embriagaram". Béate imagina, então, que as pessoas que vira em companhia dele também poderiam ter participado do ato terrível.

Diante do desespero e do indizível desamparo de Hugo, ela o puxará, no fundo do barco, para junto dela. Beijam-se, amam-se. Sentia-se beijando "pela primeira vez alguém que ela jamais conhecera e que tinha sido seu marido". Voltando a si, numa nova passagem ao ato, e desta vez radicalmente passiva diante de seu enigma, ela dará fim à vida de seu filho, que se deixa levar, e a sua própria vida.

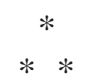

A violência situa-se no fundamento da atividade psíquica humana e de toda organização social. Submetido à sexualidade, que envolve sempre uma base de violência pulsional, o sujeito é obrigado a domesticá-la. A puberdade é uma de suas maiores ilustrações; muitas vezes acontece de a fantasia vir a dar lugar a uma violência atuada na realidade. A puberdade pode ser traumática, violenta, na medida em que implica um duplo movimento: por um lado, a efração das transformações corporais como se viessem de fora, do exterior, por outro, o surgimento de toda uma nova dinâmica pulsional, ameaçando, do interior, o equilíbrio narcísico do sujeito.

Segundo Marty (1997), o trabalho de transformações, fisiológicas e psicológicas, envolvido na adolescência já pode ser considerado violento pelo simples fato de ser um trabalho imposto; o adolescente é, de certa forma, "vítima", como mostra o autor, vítima de uma mudança que ele não pode controlar. Essa reorganização completa de si, no âmbito da identidade tanto corporal, psicológica como sexual, 


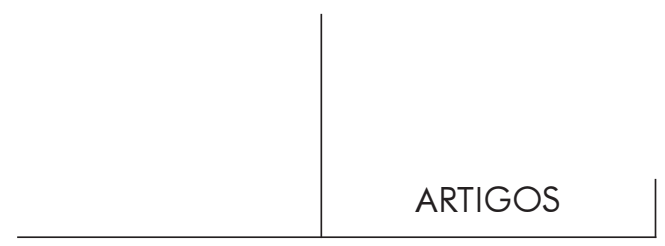

escapam, em grande parte, da possibilidade de determinação, de elaboração por parte do próprio sujeito. É o que ilustra, dentre muitos outros aspectos, o romance de Schnitzler.

Na psicanálise os contornos metapsicológicos da noção de violência são bastante imprecisos e, conforme alguns autores indicam, a idéia de trauma parece ser a que dela mais se aproxima. Presente na psicanálise desde os primeiros escritos de Freud, a noção de trauma está na própria base de sua concepção de aparelho psíquico. A tarefa principal desse aparelho é a de dominar o excesso de excitação, evitando o desprazer e a dor. A questão do trauma ultrapassa, assim, as fronteiras da constituição da teoria freudiana; ela se situa nas origens do psiquismo, nos limites do analisável e da representação (Lejarraga, 1996).

Sabe-se que após o abandono da teoria da sedução (primeira teoria traumática), a dimensão do trauma vai retornar de forma insistente na teoria freudiana a partir do tournant dos anos 1920. Com a introdução da pulsão de morte - vindo, inclusive, dar conta das situações de caráter mais violento e radical da psicopatologia individual e coletiva - o trauma torna-se um termo constitutivo da metapsicologia. Articulado à segunda teoria pulsional, e profundamente relacionado, depois, com a angústia, ele passa a estar presente, também, nas origens do psiquismo.

$\mathrm{O}$ trauma ressurge na teoria freudiana como algo que escapa à ordem das representações, registro do inassimilável, do "intraduzível”. Tanto as excitações vindas do exterior quanto as excitações pulsionais produzem efeitos traumáticos num ego incipiente, marcas de uma situação de desamparo originário, situação de passividade fundamental diante do outro: situação de inescapável submissão do sujeito, na qual se reencontra, de forma privilegiada, a dimensão de alteridade e a de sexualidade.

Vemos, então, que a noção de excesso entrelaça-se à questão do desamparo psíquico. Jean Laplanche (1990) explora essa articulação de maneira bastante interessante em sua teoria da sedução generalizada. A excitação, excesso vindo de fora - do "outro" - que ultrapassa a capacidade de metabolização do infans, permite que este, paradoxalmente, possa se organizar psiquicamente.

O ponto a ser aqui ressaltado é a própria alteridade do adulto em relação a si mesmo, a implicação de seu próprio inconsciente nas mensagens (enigmáticas) que ele endereça à criança. A "transferência" desse enigma - fundamento de uma situação originária necessariamente violenta e traumática - constitui o modelo básico do próprio processo de recalcamento originário, da constituição do inconsciente e da pulsão.

Situações envolvendo profunda ruptura, em especial aquelas que incidem diretamente sobre a dinâmica pulsional e sobre a economia libidinal, produzem no sujeito a repetição da experiência de passividade, de desamparo e, conseqüentemente, a exigência de dominar esse estrangeiro interno. A noção de desamparo possui 


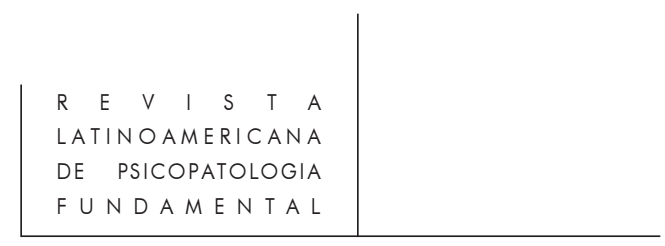

uma significação bastante abrangente, pois configura uma dimensão básica da subjetividade humana, e que se entrelaça profundamente com a cultura. Dizia Freud, já nos primórdios de seu percurso, que "o desamparo inicial dos seres humanos é a fonte primordial de todos os motivos morais" (Freud, 1940: 336). Encontramos aí uma valiosa via, ainda que implícita, de que o desamparo indica sobretudo que o psiquismo está condenado a se constituir e a existir na relação com o outro.

A noção de desamparo atinge de forma especial a problemática aqui abordada, constituindo uma espécie de elo entre diferentes situações vividas na adolescência, particularmente as situações de ruptura e perda (da infância, dos pais da vida infantil, do corpo infantil, das referências identificatórias etc.). Essas implicam, muitas vezes, precariedade quanto à resposta psíquica do sujeito, passivo diante de um excesso pulsional - irrupção de energia não ligada - que, por sua vez, é relativo à fragilidade dos mecanismos narcísicos, egóicos, inevitavelmente transtornados nessa travessia da adolescência.

A questão do excesso pulsional e, nessa perspectiva, a da pulsão de morte, articula-se com um dos aspectos mais significativos da adolescência - é o que o romance de Schnitzler explora, em caricatura: a revivência do Édipo. A problemática edípica reapresenta-se na adolescência sobre um fundo bem diferente daquele que apóia o Édipo infantil. A possibilidade efetiva da realização do ato sexual marca uma diferença fundamental tanto para o sujeito em sua relação com o outro, quanto para o outro parental confrontado com sua própria alteridade interna.

O sujeito adolescente deve poder distinguir - e esse é um dos desafios colocados por essa experiência de "fronteiras" - entre o que é a sua própria história, o que advém de uma fonte interna, e tudo aquilo que vem do outro, do desejo do outro e, em primeiro lugar, do outro parental. A intromissão desse outro, de sua alteridade, pode constituir obstáculo ao processo e, de acordo com as suas dimensões narcísicas e edípicas, muitas vezes arcaicas, pode vir a invadi-lo, parasitá-lo. A esse respeito Green (1999) fala de "colonização do sujeito" ou de "efeito captador sobre o funcionamento psíquico". Mostra ainda o autor que é preciso que se "negative" o Édipo, no sentido de sua destruição, já que ele é intolerável nesse novo corpo. "Todas as mães o sabem. Há um momento em que não se acaricia mais a criança, hesita-se três vezes antes do carinho sobre a face, que sabe Deus, é bem inocente! Elas não dizem, mas sabem" (Ibid.: 77).

A dimensão de mudança é um elemento dos mais significativos da noção de trauma, ligado que este é ao risco colocado pela própria mudança. Trata-se aqui do caráter inesperado, siderante, das transformações. A adolescência constitui em si mesma uma espécie de paradigma da mudança. A transição da vida infantil para a vida adulta não configuraria, dessa maneira, uma situação fronteiriça? A adolescência é uma problemática ligada à questão de fronteiras, ao mesmo tempo internas 


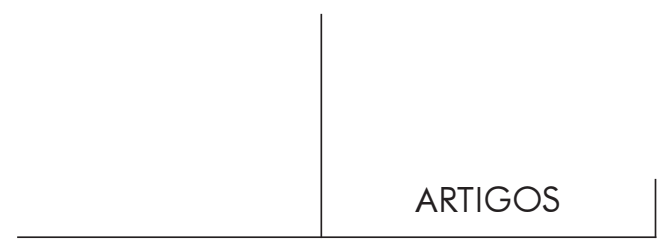

- relativas ao próprio funcionamento psíquico do sujeito, sua relação com o outro interno - e externas, ligadas à relação do sujeito com a alteridade externa, com a diferença.

A obra freudiana fornece uma visão da própria constituição egóica - das fronteiras do ego - como uma modalidade de defesa, para dar conta dos ataques advindos das pulsões internas assim como do exterior. Luís Claudio Figueiredo (2000), apoiando-se em vários autores que se dedicaram à teoria e à clínica dos estadoslimite, no rico trabalho apresentado na II Jornada da SCPRJ ${ }^{1}$, aponta as duas angústias características dos fronteiriços: a de abandono, separação e perda e a angústia de invasão pelo objeto. Tanto a questão do abandono e da perda como a da invasão - da intromissão do outro, diria Laplanche - remetem-nos às "doenças das fronteiras do ser", situações marcadas pela precariedade dos espaços psíquicos, dos limites externos e internos, incidindo forte e simultaneamente sobre o eixo narcísico e alteritário.

\section{Referências bibliográficas}

BIRMAn, J. Estilo e modernidade em psicanálise. São Paulo: Ed. 34, 1997. . Psicanálise, negatividade, heretogêneo: como a psicanálise pode ser obstáculo para a barbárie. Cadernos de Psicanálise da SPCRJ, vol. 15, nำ18, 1999.

Figueiredo, L. C. O caso-limite e as sabotagens do prazer. Revista Latinoamericana de Psicopatologia Fundamental, vol. III, no 2, junho de 2000.

FREUd, S. (1940[1895]). Projeto para uma psicologia científica. E.S.B. Rio de Janeiro: Imago, 1980. vol. I.

(1930). O mal-estar na civilização. E.S.B. Op. cit. v. XXI.

GreEn, A. Intervenção no Colloque avec André Green (17 ${ }^{a}$ Journée Scientitique de la revue Adolescence-Unesco, outubro de 1998). Adolescence, t. 17, no 1, 1999.

Gutton, P. Intervenção no Colloque avec André Green (17 Jornée Scientifique de la revue Adolescence-Unesco, outubro de 1998). Adolescence, t. 17, no 1, 1999.

MARTY, F. (org.). L'illegitime violence: la violence et son dépassement à l'adolescence. Paris: Editions Erès, 1997.

LaPlanche, J. Nouveaux fondements pour la psychanalyse. Paris: PUF, 1990. . La révolution copernicienne inachevée. Paris: Aubier, 1992.

Lejarraga, A. L. O trauma e seus destinos. Rio de Janeiro: Revinter, 1996.

Schnitzler, A. (1913). Madame Béate et son fils. Paris: Stock, 1987.

1. Jornada da Sociedade de Psicanálise da Cidade do Rio de Janeiro sobre o tema "Casos-limite" - 24-25 de setembro de 1999. 


\section{Resumos}

Uno de los principales objectivos de este trabajo es el estudio de la articulación entre violencia pulsional y adolescencia, buscandose subrayar los aspectos traumáticos envolvidos en este pasaje. Es destacada la questión de la revivencia del complejo de Édipo y especialmente su resonancia muchas veces igualmente traumática en el psiquismo de los padres.

Un belisimo y trágico romance de Arthur Schnitzler (1913), Frau Beate und ihr Sohn - relato de múltiples pasajes al acto apoyados simultaneamente en los vividos inconscientes de una madre y de su hijo adolescente delante de un intraducible "malestar" - inspira y ayuda la elaboración de las ideas presentadas

Palabras llave: Adolescencia, violencia, pulsión, complejo de Édipo

Développer l'articulation entre violence pulsionnelle et adolescence c'est un des objectifs principaux de ce travail dans lequel on essaye de souligner les aspects traumatiques propres à ce passage. La question de la reviviscence de l'Oedipe est mise en relief, tout particulièrement le fait de sa résonance, souvent aussi traumatique dans la vie psychique des parents.

Le beau et tragique roman d'Arthur Schnitzler (1913) - Madame Béate et son

36 fils - récit de multiples passages à l'acte, étayées simultanément dans les vécus inconscients d'une mère et de son fils adolescent face à un malaise intraduisible, inspire et renforce l'elaboration des idées presentées.

Mots clés: Adolescence, violence, pulsion, Complexe d' Oedipe

One of the main aims of this paper is to link drive-related violence and adolescence. The author underlines the traumatic features related to that period of life. The question of reliving the Oedipus complex is also emphasized, especially its repercussions, that are often traumatic for the psyche of the parents as well.

A beautiful and tragic novel by Arthur Schnitzler (1913) - Frau Beate und ihr Sohn, which describes numerous episodes of acting out grounded simultaneously in the unconscious experiences of a mother and of her son when faced with an untranslatable "discontent"- inspires and supports the development of the ideas presented.

Key words: Adolescence, violence, drive, Oedipus complex

Versão inicial recebida em agosto de 2000.

Versão revisada recebida em novembro de 2000. 